\title{
PAPULAR URTICARIA (LICHEN URTICATUS)
}

\author{
By B. C. TATE, M.A., M.D., M.R.C.P.
}

(Physician to the Skin Departments, the General and Children's Hospitals, Birmingham.)

Although papular urticaria is, perhaps, the commonest of all the skin disorders of childhood, it receives but scant mention in most of the textbooks on dermatology or paediatrics, and relatively few systematic investigations of the disease have been made. This neglect can doubtless be attributed to the benign character of the complaint: it is not a direct menace to life, nor does it constitute a permanent disability. Nevertheless it is an important childish ailment, not only on account of its great frequency, but also because it occasions a good deal of misery in those whom it afflicts, and much anxiety in those responsible for their care.

In spite of the large amount of material available for study, no agreement has been reached either as to the nature or aetiology of the complaint, nor has a satisfactory treatment been discovered. This inquiry was undertaken to see what light could be thrown on these problems, especially that of aetiology, by the analysis of the records of 299 patients under twelve years of age who attended the skin department of the Children's Hospital, Birmingham, between January, 1930, and December, 1933; and by a few simple experiments in a smaller number of selected cases.

It is not proposed to review in detail the whole of the past literature on the subject, but a few salient points require mention. Ever since the appearance of Bateman's first description, and probably before that, papular urticaria has been recognized as essentially a disease of early childhood, and equally well known is the aggravation of the symptoms by heat, hence the popular term ' heat spots.' In addition to these two factors, its cause has been ascribed to a wide variety of agents and conditions. These many different views are not necessarily mutually exclusive. Papular urticaria might be a cutaneous reaction which can be evoked by a number of different stimuli, and some of the alleged causes, while not exciting agents, might predispose to, or aggravate the disease. For a long time, digestive disorders were, by most observers, placed first in the list of causes, but in more recent years the condition has been accepted almost universally as a manifestation of allergy. Much difference of opinion still remains, however, concerning the nature of the allergen. Food is usually regarded as the offender, proteins being most often incriminated, but carbohydrates have also been blamed, while Bray 
assigns chief place to fats, especially those derived from pork. Strikingly at variance with the commonly accepted views are the experiments of Tilbury Fox and Hallam, who showed that merely admitting patients to hospital brought about rapid cure, relapse occurring only on their return home. As a result of dietetic and other experiments with patients in hospital, Hallam came to the conclusion that the cause of papular urticaria is not food, but some environmental factor.

The experimental approach is obviously the best method of determining the exciting cause of the disease, but Hallam's researches left out of consideration certain other important influences, notably the effect of heat. The present series of experiments was therefore undertaken with a view to rectifying such omissions, and it may be stated here that the results largely confirm Hallam's views. The experimental method, however, throws but little light on predisposing factors, so that a more extensive review of the subject was deemed advisable.

\section{The nature of papular urticaria.}

In its clinical features, papular urticaria bears resemblances to two conditions, the ordinary urticaria of adults, and Hebra's prurigo. Lewis has shown that the urticarial reaction in adults is a triple response to a histamine-like substance, 'H-substance,' acting locally on the vessels of the skin. Papular urticaria, however, is a quadruple response : will $\mathbf{H}$ substance, acting on a child's skin, produce the additional element, the papule?

The effect of histamine. A 1 in 1,000 solution of histamine phosphate was pricked into the skin of a patient who had been subjètect to papular urticaria for two years, and who was actually suffering from an attack. Whealing occurred exactly as in normal controls. The wheals had completely subsided at the end of two hours, leaving no palpable or visible trace at all.

The effect of ' $\mathbf{H}$-substance.' - Small pieces of nettle leaf were applied to the skin of the same patient, and again whealing occurred in the usual manner, without any suggestion of papule formation. H-substance may be liberated, and an urticarial response evoked, by insect bites. In two cases I have had the opportunity of observing recent flea bites in sufferers from papular urticaria. In each instance the bites produced prominent wheals, which, subsiding after about two hours, left behind minute red puncta, but no trace of papules. Hallam has shown that the bite of a bug results, in such children, in an urticarial reaction, but it does not leave the characteristic papule.

It is clear, therefore, that external stimuli which evoke an ordinary urticarial reaction in adults, evoke precisely the same response in children, even though the children be subject to papular urticaria. It is more difficult to test stimuli acting from within, but there is one such agent, the effects of which are seen relatively often. The injection of animal 
serum is frequently followed by urticaria, both in children and adults, and the urticaria which it causes in children is of the ordinary form, never papular urticaria. It is true that, except for this serum rash, typical urticaria is not common in children, but it does occur, and is probably not so rare as is usually supposed: I have seen some dozen or more examples of it during the past four years.

Lastly, quite apart from external agents or serum, urticaria and papular urticaria may occur independently in the same patient. This is not merely an example of a single disease undergoing a change of form, for the two reactions are provoked by different exciting stimuli. This is clearly illustrated by the following case :-

D.S., a female, was first brought to hospital at the age of twelve months, suffering from generalized eczema of eight months duration. This cleared up under treatment, although slight outbreaks in the flexures still appeared from time to time. At the age of seventeen months, she was given fish for the first time in her life, and within a few hours the face became swollen and the body and limbs covered with large white wheals, which in every way resembled those of urticaria as seen in the adult. The whole condition rapidly subsided, leaving behind no trace. At the age of twenty months, she began to suffer from papular urticaria, although she was not then having fish. In order to decide whether this was a case of urticaria which had changed its form, fish was again administered, and again there was the same acute outbreak of true urticaria, which, as before, rapidly subsided without the slightest evidence of papule formation.

It must be concluded, therefore, that although papular urticaria has certain features in common with true urticaria, it is essentially a cifferent reaction, and the assumption of a common aetiology is not justified.

Among Continental authors it is customary to class papular urticaria as a prurigo, and it has been suggested from time to time that it is an early stage of the prurigo of Hebra. There are, however, important differences between these two conditions. Heath has pointed out that the eruption on the limbs is much more rigidly restricted to the extensor surfaces in Hebra's prurigo. Whitfield has emphasized the early appearance of secondary skin changes in Hebra's prurigo and their absence in papular urticaria, even in cases of long standing. Both conditions show a seasonal variation, but whereas Hebra's prurigo is said to improve during the summer, papular urticaria usually gets worse at this time. Most important is the difference between the individual papules in the two diseases. The early papule of Hebra's prurigo is deeply set, being more easily detected by touch than by sight; that of papular urticaria is superficial, and is usually capped by a minute vesicle. Not only is this difference apparent clinically, but Civatte has demonstrated it clearly from the histological standpoint. 
It is clear, therefore, that papular urticaria is a distinct morbid condition, separable from urticaria and from the prurigo of Hebra. In the evolution of its lesions an urticarial reaction does occur, but there is an additional element, the papule. This papule cannot be evoked by the urticaria-producing agent, $\mathrm{H}$-substance, and it is of a different nature from the papule of Hebra's prurigo : the physiological significance of its formation is not understood.

\section{Incidence of papular urticaria.}

Papular urticaria appears to be a common complaint in Great Britain and on the continent of Europe, especially in France, Germany and Denmark: it is comparatively rare in the United States of America (Duhring, Montgomery).

It is very prevalent in Birmingham, as in most large English towns, and, during the period under review, accounted for over sixteen per cent. of all the cases admitted to the Skin Department at the Children's Hospital (table 1).

TABLE 1.

\begin{tabular}{|c|c|c|c|}
\hline YeaRLy & INCIDENCE O & Papular & UR'TICARIA, 1930-1934. \\
\hline Y YaR. & Number o & CASEs. & Per cent. of all skin cases. \\
\hline 1930 & 74 & & 18.9 \\
\hline 1931 & 93 & & 18 \\
\hline 1932 & 87 & & 16 \\
\hline 1933 & 45 & & 11.8 \\
\hline & TOtaL 299 & & 16.4 \\
\hline
\end{tabular}

It will be noticed that there was a striking decrease of papular urticaria in 1933, an unexpected finding in view of the hot summer of that year. These figures give no more than a rough impression of the true incidence of the complaint among the whole child population; there is no doubt that medical advice is sought in only a minority of cases.

Sex incidence.-The sexes were almost equally represented, there being 154 boys and 145 girls.

Age incidence.-The youngest patient seen was aged one month, the oldest eleven years. The earliest age at which the rash was said to have commenced was three days, the latest seven years. The disease often begins mildly and insidiously, and many parents, disregarding the first few attacks, were unable to state the age of onset with precision. Most, however, could place the onset within a period of three months. The age of onset was determined with this degree of accuracy in 250 cases (table 2), 
TABLE 2.

Age incidence of Papular Urticaria.

Age at onset. Age on admission to hospital.

\begin{tabular}{|c|c|c|c|c|}
\hline & & & & \\
\hline Years. & No. OF CASES. & Per cent. & No. OF CASES. & Per cent. \\
\hline $0-1$ & & 50 & 41 & \\
\hline $1-2$ & 68 & 27.2 & 65 & 21.7 \\
\hline $2-3$ & 31 & 12.4 & 80 & 26.7 \\
\hline $3-4$ & 14 & 5.6 & 41 & 13.7 \\
\hline $4-5$ & 5 & 2.0 & 25 & 8.4 \\
\hline $5-6$ & 2 & 0.8 & 14 & 4.7 \\
\hline $6-7$ & 4 & 1.6 & 11 & 3.7 \\
\hline $7-8$ & 1 & 0.4 & 7 & 2.3 \\
\hline $8-9$ & - & - & 7 & 2.3 \\
\hline $9-10$ & - & - & 6 & 2.0 \\
\hline $10-11$ & - & - & 1 & 0.3 \\
\hline $11-12$ & - & - & 1 & 0.3 \\
\hline & 250 & & 299 & \\
\hline
\end{tabular}

It will be seen that the disease begins most commonly (50 per cent. of cases) during the first year of life, and very rarely after the fourth year. A further analysis shows that the onset is especially common during the first nine months of life, and that there is an appreciable increase in the frequency of its occurrence between the ages of six and nine months, the period when teething commonly begins (table 3).

TABLE 3.

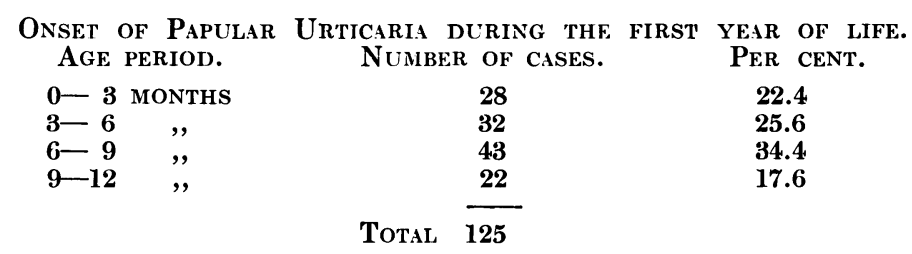

The age on admission to hospital is of some importance because it seems reasonable to assume that most patients are brought when the disease is at its worst. Table 2 shows that the great majority of patients were under the age of four years on their first attendance at hospital, and nearly half were aged between twelve months and three years.

It may be concluded, therefore, that papular urticaria, although not strictly confined to any special age period, is essentially a disease of the first four years, beginning most frequently during the first nine months of life, and attaining its maximum severity during the second and third years.

Seasonal incidence.-Attacks may occur at any time of the year, but the disease is much more prevalent in summer than in winter. The month in which the first attack occurred was determined in 158 cases. Of these, 101 (64 per cent.) had their first onset during the six warmer months, April to September, and 57 (36 per cent.) during the six colder months, October to March. The seasonal incidence is not entirely attributable to the higher temperature of summer. The monthly admissions for papular urticaria, which may be taken as a guide to the 
seasonal variations in its severity, are shown in fig. 1, and are compared with the mean monthly temperatures over the same period.

There was a distinct bi-annual rise in the number of admissions, most patients attending for the first time in September, and the next highest number in late spring. It is obvious that no strict correlation exists between the atmospheric temperature and the prevalence of papular urticaria.

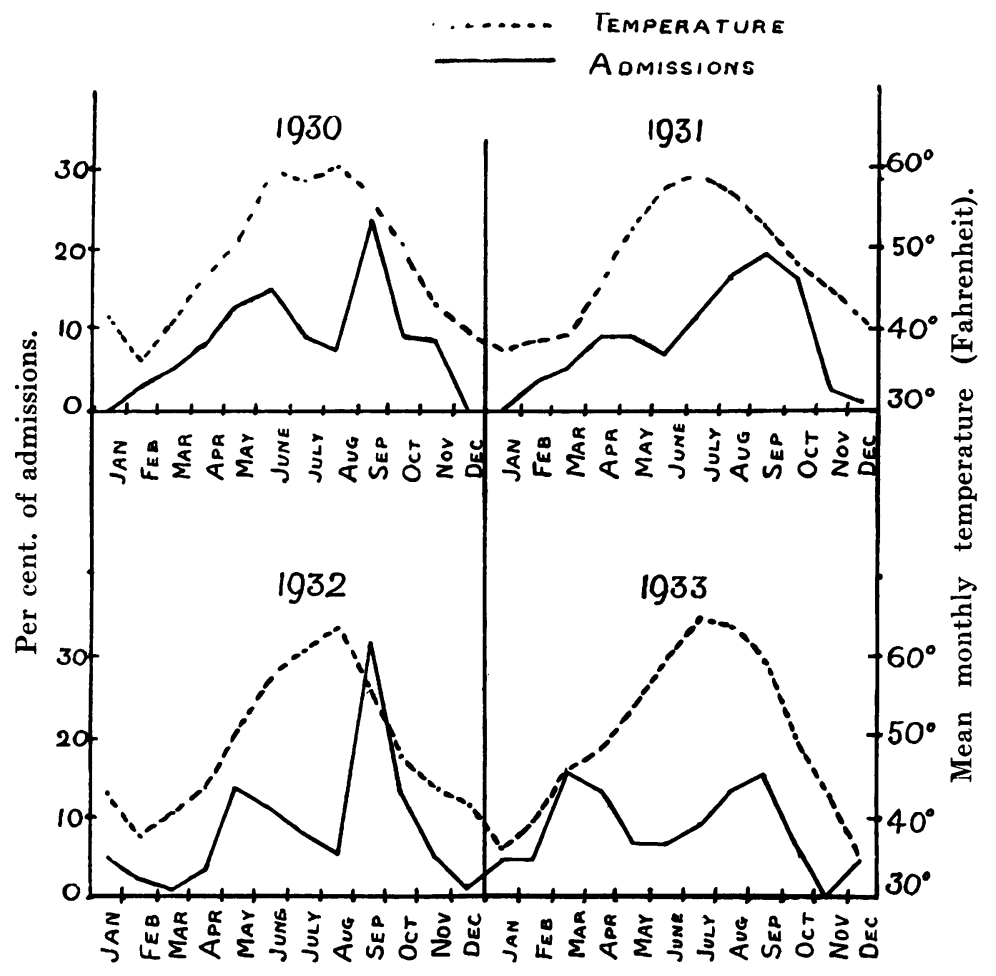

Fig. 1.

MONTHLY ADMISSIONS IN RELATION TO TEMPERATURE.

There does, however, seem to be some connection with diet. Late spring and early autumn, the periods when the admissions are greatest, are also periods when the carbohydrate content of the diet tends to be increased, especially among the poor. These are the seasons when stewed fruit becomes cheap and therefore popular-rhubarb in late spring, plums, blackberries, etc., in early autumn-and these dishes are served with large amounts of sugar. In early autumn, fresh fruit also becomes plentiful, so that the carbohydrates of the diet are still further increased; and in addition, although the atmospheric temperature is falling, it still reaches levels high enough to affect the disease.

Haxthausen found that in Copenhagen, there was a big increase in the number of cases coincident with the period of ripening of the commoner fruits. He was unable to demonstrate any direct connection between the prevalence of the disease and weather conditions, 
Social status. - The worst cases occurred among the poorer patients, but many came from comparatively good homes. Of the present series of patients 82 per cent. belonged to families of three or less children, and 35 per cent. were only children : in these cases poverty or parental neglect are unlikely to be major factors. There is no doubt that the disease is of frequent occurrence in all social grades.

\section{Diathesis.}

Since papular urticaria is commonly held to be allergic, the persona! and family histories of the patients were investigated for other manifestations of allergy. Inquiries were made into the personal histories for symptoms of eczema, asthma and, in older children, hay fever. The family histories were examined for eczema, urticaria, asthma, hay fever, and migraine. A fairly complete personal history was forthcoming in 270 cases, but the family history was not taken in the earlier stages of the inquiry, and was obtained in only 208 cases. The results may be summarized thus :-

\section{Personal History.}

Total number of cases $\quad \ldots \quad \ldots \quad \ldots \quad 270$

Of these, a history of allergic diseases was given in 4, or 1.5 per cent. These comprised :-

$\begin{array}{lccccccl}\text { Infantile facial eczema } & \ldots & \ldots & \ldots & & 1 \text { case } \\ \text { Flexural } & \text { eczema } & (\text { Besnier's } & \text { prurigo) } & \ldots & & 2 & \text { cases } \\ \text { Asthma } & \ldots & \ldots & \ldots & \ldots & \ldots & 1 & \text { case }\end{array}$

No special inquiry was made for enuresis, which Bray includes as an allergic condition, and which he believes to be commonly associated with papular urticaria, but a history of this complaint was volunteered in only seven cases (2.6 per cent.).

\section{Family History.}

$\begin{array}{lllll}\text { Total number of cases } & \ldots & \ldots & \ldots & 208\end{array}$

Of these, a history of allergic diseases was obtained in 29 or 13.9 per cent.

These comprised :-

\begin{tabular}{|c|c|c|c|c|c|c|c|c|}
\hline Eczema & & $\ldots$ & .. & & $\ldots$ & in & 13 & cases \\
\hline Urticaria & (or a) & o-ne & tic & oedema) & ... & & - & ," \\
\hline Asthma & $\ldots$ & $\ldots$ & $\ldots$ & $\cdots$ & $\ldots$ & & 12 & ," \\
\hline Hay fever & $r \quad \ldots$ & $\cdots$ & $\cdots$ & & $\cdots$ & , & 7 & \\
\hline Migraine & $\ldots$ & $\ldots$ & $\ldots$ & $\ldots$ & $\ldots$ & ,, & 2 & , \\
\hline
\end{tabular}

If eczema be excluded, it is found that only 9.6 per cent. of cases had a family history of allergic disease, while if only asthma and hay fever be considered, this figure is reduced to 8.6 per cent.

These figures approximate very closely to those obtained by other observers for normal persons, and are in striking contrast to those for a 
series of asthmatics. Spain and Cooke, considering asthma and hay fever only, obtained a positive family history of allergy in 7 per cent. of a series of 115 normal persons; Balyeat in 8.3 per cent. of a series of 1,117 normal persons. Cooke and Vander Veer, including urticaria, angioneurotic oedema and gastro-intestinal allergy in addition to asthma and hay fever, obtained a positive family history in 12.2 per cent. of 139 normal cases. In Bray's series of 200 asthmatic children on the other hand, there was a positive family history of allergy in 68.5 per cent. O'Keefe and Rackemann, while not specifying what diseases they counted as allergic, stated that there was a positive family history in 28 per cent. of 212 cases of eczema in children.

It appears from these figures that the occurrence of other allergic manifestations, either in the personal history or in the family history, of patients with papular urticaria, is no more frequent than in a series of normal people.

A further point of importance in this connection is the sex incidence. It has repeatedly been shown that both eczema and asthma, when occurring in early childhood, affect boys more often than girls in the proportion of about $3: 1$. Papular urticaria affects the sexes equally.

It is improbable, therefore, that there can be a hereditary predisposition common to papular urticaria and the other allergic diseases; nor does there seem to be any adequate reason for including the condition in either the so-called exudative or neuro-arthritic diathesis.

\section{Association with other conditions.}

Teething.-In 10 per cent. of patients the rash first appeared before the age of three months, and in a further 10 per cent. after the age of three years; that is, in 20 per cent. of cases teething can be definitely excluded as a cause of the disorder. In 37 per cent. of cases the rash persisted after dentition was complete. Nevertheless the onset of the complaint does seem to occur with greater frequency between the ages of six and nine months, the period when teething commonly begins, than during any other age period of like duration (see table 3). Further, in several cases the parents were quite sure that not only did the onset of dentition determine the onset of the rash, but also that the cutting of each subsequent tooth caused an exacerbation.

Darier, who ascribes a good deal of importance to dentition in this complaint, maintains that an outbreak of the rash is not uncommon during the cutting of the wisdom teeth. In my experience papular urticaria is rare at this period of life, but $I$ have seen it in a girl of seventeen : and in this patient the lower wisdom teeth were just appearing. It seems probable, therefore, that dentition is a definite predisposing factor in some cases.

Digestive disorders. - A history of digestive disturbances was volunteered by the parents in only a few cases, but because of the opinions so 
frequently expressed in the literature, detailed inquiries for symptoms referable to the alimentary system were made in 150 cases :-

$\begin{array}{lrrr}\text { Total number of cases } & \ldots & 150 \\ \text { Negative history } & \ldots & \ldots & 125 \text { cases or } 83.3 \text { per cent. } \\ \text { Positive history } & \ldots & \ldots & 25 \text { cases or } 16.7 \text { per cent. }\end{array}$

The symptoms complained of comprised :-

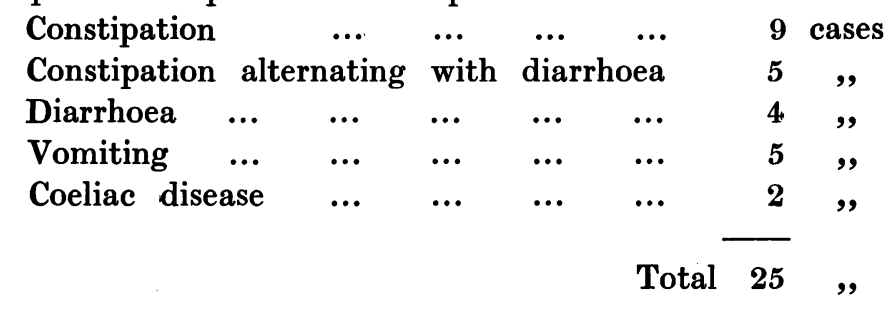

It is very difficult to estimate the significance of these findings. Constipation is common enough throughout life, while attacks of vomiting and diarrhoea are frequent accidents of childhood, so that their occurrence in association with such a common disease as papular urticaria is not surprising. Neither Czerny, Karplus, Hallam nor Winkler observed any great prevalence of digestive disorders among their patients. Corson and his co-workers, in a study of 31 cases, found the state of nutrition of the children good, the appetite healthy, and in 21 cases the bowels were regular.

Sometimes, however, there does seem to be a definite relation between the alimentary symptoms and the rash, as in one case where the mother stated that each fresh outbreak was always heralded by vomiting. It seems probable, therefore, that digestive disorders may predispose to papular urticaria, but it is obvious that their importance in this respect has usually been greatly overestimated.

Intestinal worms. - A history of threadworms was elicited in four cases only. In one of these, the worms had been discovered and treated five months before the onset of the rash. Corson found threadworms in the faeces of only one out of 31 cases; Hallam in only one of 51 cases. Hellsten finds that, in children, the incidence of threadworm infestation increases with age, reaching a maximum between the ages of 10 and 15 years. Papular urticaria on the other hand, decreases with advancing years. There can be little doubt, therefore, that the occurrence of threadworms in association with papular urticaria is purely fortuitous.

Febrile disturbances.- In twelve cases the onset of the rash was thought by the parents to be related to the following conditions :vaccination in five cases; varicella in three cases; measles in two cases; and diphtheria in two cases.

The rash first appeared a week after vaccination in each of the patients where this was held responsible, but showed no definite time relationship to the other conditions. 
In no patient admitted to hospital was bacilluria discovered, nor was this found by either Hallam or Corson in any of their patients.

I have no statistics relating to the occurrence of colds among my patients. It is significant that papular urticaria begins most frequently, and is usually most severe, during the summer months, when colds are not specially rife.

The short interval elapsing between the onset of the rash and vaccination suggests that there may be some connection between the two condtions. Parents, however, are only too ready to blame vaccination for any childish ailment, and the fact that it was incriminated in so few cases shows that it can, at the most, be of only very minor importance. The evidence relating to other febrile disturbances is entirely unconvincing.

\section{Evidence relating to diet.}

The diet of patients under the age of nine months.-Of the 250 cases in which the age of onset was determined, the symptoms commenced during the first nine months of life in 103 , i.e., 41 per cent. In twelve of these, no record of the diet was kept. The mode of feeding at the onset of the complaint in the other 91 patients is set forth, together with a control series, in table 4. As a control, the diets of 100 infants, under the age of nine months, who attended hospital for naevi and for certain surgical conditions such as burns, scalds, fractures and hernia were investigated.

Nature OF Diet.

Breast only

Breast with supplementary feeds $\ldots$

Artificial feeds only ...

\section{TABLE 4.}

$\begin{array}{cc}\text { Patients with Papular } & \text { Controls. } \\ \text { Urticaria (91 Casks). } & \text { (100 cases.) } \\ \text { Per cent. } & \text { Per Cent. } \\ 42.9 & 45 \\ 3.3 & 2 \\ 53.8 & 53\end{array}$

It will be seen that the figures for the two groups approximate so closely that it may reasonably be concluded that papular urticaria attacks indiscriminately both breast-fed and bottle-fed infants under the age of nine months. Since this is the period when the onset of the complaint occurs with the greatest frequency, these findings furnish strong evidence that diet can play no more than a minor part in the aetiology.

The diet of older patients. - It was impossible to keep an accurate record of the children's diets after the age of about nine months, but the opinion was formed that in many instances, and especially among the poorer patients, the carbohydrate intake was unduly high.

In most cases, inquiries were made to find out whether or not the onset, or exacerbations, of the symptoms seemed to be related to the administration of particular foods. In only 29 instances were the parents definitely of opinion that diet had any influence, but a consideration of the foods incriminated is rather instructive. They were as follows, the figures in brackets being the number of cases:-bananas (12); apples (7); oranges (1); fresh fruit (any kind) (1); stewed fruit (2); tinned fruit (2); 
sweets and sugar (7); cake (2); shredded wheat (3); porridge (1); new bread (1); fish (3); cod liver oil (2); and bacon fat (1).

The striking feature of this list is the frequency with which foods of a high carbohydrate content occur; and in every case where the food was of this nature, its removal from the diet, together with a restriction of carbohydrate in general, was followed by rapid improvement. Further, a great improvement was noticed in many other patients on a restricted carbohydrate diet, even when no particular food had been blamed by the parents; and the improvement, in chronic cases, is frequently so rapid that it does not seem possible to ascribe it to any other cause. Moreover, in some cases, after apparent cure, it was possible to provoke the eruption again by re-introducing large amounts of carbohydrate into the diet, a phenomenon which has also been observed by Mathieu and his co-workers. This is well illustrated by the following case :-

B.H., a male, was first brought to hospital at the age of three years in August, 1931, with a history of frequent attacks of papular urticaria since the age of nine months. It was noticed that the eruption always seemed worse after bananas and shredded wheat. These were excluded from the diet, the carbohydrate intake generally restricted, and a soda and rhubarb mixture was given. There was an obvious improvement, and by October the lesions had ceased to appear. In January, 1932, porridge was added to the diet, and a fresh outbreak occurred immediately. Porridge was discontinued, and by the middle of February the boy was well. On March 24 there was a very profuse outbreak, and, on inquiry, it was found that the previous day was the boy's birthday, in the celebration of which he had eaten large quantities of sweets and cakes. Dietetic restrictions were again observed, and by the middle of April recovery seemed complete. In June there was a further slight attack, for which no dietetic cause was discovered. In August the inclusion of stewed plums in the diet was followed by another severe outbreak of the rash. Rapid improvement again occurred when this food was omitted; and, except for a very few occasional lesions, not sufficient to cause the boy any discomfort or the parents any anxiety, he has remained well since.

In this patient it will be noticed that outbreaks of the rash occurred even when the diet was regulated, but they were never so severe as those which occurred after the addition of extra carbohydrate to the diet. It is also instructive to note that a variety of foods seemed to precipitate an attack-bananas, shredded wheat, porridge, sweets, cakes and stewed plums-and the one feature common to them all is their high carbohydrate content.

Crocker, Mathieu, Weigart and Gray all mention excessive carbohydrate feeding as a cause of the disease. The harmful influence of bananas has been observed by Burgess, and Walker has blamed stewed rhubarb, a food which is always served with a large amount of sugar. These findings account, in part at any rate, for the seasonal variations in the severity of the disease. 
The mode of action of these carbohydrate foods is obscure. It seems to be a quantitative effect, not an allergic phenomenon. Symptoms of digestive disorder were present in only 16.7 per cent. of cases; and in several instances, selected at random, the stools showed no excess of organic acids, and no evidence of excessive fermentation, so that Mathieu's ' acid' colitis hypothesis is untenable.

It must be emphasized that overfeeding with carbohydrate is not an essential and constant factor in the disease. Breast-fed infants are attacked, and in some of the older children, careful dieting fails to produce any improvement. It is very unlikely, therefore, that in severe cases, such as Hallam investigated, their recovery on admission to a hospital ward could be due to a mere quantitative change in the carbohydrate content of the diet. Nevertheless, in experimental attempts to provoke the eruption, it would seem advisable to provide the children with a liberal carbohydrate ration.

Vitamin deficiency. - The foregoing analysis does not suggest vitamin deficiency as an important factor in papular urticaria, but Funk and Grundzach, and Comby have reported a frequent association with rickets. Slight rickets is notoriously difficult to diagnose clinically. Radiological examination of three of the present series of patients, in whom rickets was suspected, showed normal bones. No attempt has been made to estimate the precise incidence of rickets in the present series. Clinically discernible rickets was not common. There are three further points which suggest that there is no connection between the two diseases. Papular urticaria frequently begins during the first nine months of life, and at this age period breast feeding seems to offer no protection. Secondly, although the age incidence of papular urticaria overlaps that of rickets, it is not identical. Park and Eliot conclude that ' rickets in its active form is essentially over by the end of the third year.' Papular urticaria frequently lasts much longer; in the present series 38 per cent. of the patients were over three years of age on their first attendance at hospital. Finally, and perhaps most important, is the seasonal incidence. Chisholm has shown that in Manchester, and presumably the same would hold for similar English cities, rickets is most prevalent in late spring, and becomes less and less frequent as the summer advances, reaching a minimum in autumn. Papular urticaria on the other hand, has always been recognized as a disease of the summer months, and in the present series the attendances at hospital reached their highest peak in September.

Food allergy. - If the disease were a manifestation of food allergy, it would be necessary to assume that the breast-fed patients are sensitive either to human milk, or to something excreted in it.

Shannon claims to have shown, both by anaphylactic experiments on guinea pigs, and by clinical tests, that proteins eaten by women can be excreted in the breast milk and produce cutaneous symptoms in the suckling. His methods have been adversely criticized by Stuart, who was unable to demonstrate any excretion of foreign proteins in breast 
milk. Gebert and Lortat-Jacob attributed the disease in breast-fed infants to changes in the breast milk caused by menstruation in the mother. Sensitivity to human milk, however, whether normal or altered by menstruation, and sensitivity to any foreign proteins it may contain, seems highly improbable, for in none of the present series of patients, and in none of Hallam's, did weaning effect a cure.

No improvement was observed as a result of dietetic measures other than carbohydrate restriction. In two cases cod-liver oil, and in one case bacon fat, were thought to precipitate the attacks, but the exclusion of these articles from the diet was without effect. In view of Bray's hypothesis, complete exclusion of all pork products was advised in fifteen cases, but no benefit accrued. In three cases fish was held responsible, but the rash still appeared after the complete withdrawal of this food.

It may be said, in summing up this section, that careful inquiry and the elimination of suspected foods from the diet failed to provide any satisfactory evidence that papular urticaria is caused by food allergy. There are, however, two weak points in this type of investigation. First, if there were a long latent period between the ingestion of the allergen and the manifestation of the allergic reaction, the association between the two might escape notice; secondly, parents cannot always be relied upon to carry out dietetic restrictions. In order to obviate the first of these difficulties, cutaneous tests have been tried, but while several authors have reported an increased cutaneous sensitivity to proteins in papular urticaria, all agree, with the exception of Sidlick and Knowles, whose results are not convincing, that the tests are of no diagnostic value.

It seems, therefore, that the only satisfactory way of demonstrating that the disease is a manifestation of food allergy, is to provoke the eruption, by food, under controlled conditions.

\section{Experimental evidence.}

1. The effect of heat. - In order to investigate the effect of heat, outpatients were chosen whose rash was not very profuse, and who had developed fresh lesions on the previous day but none on the day of attendance. These patients were placed in a room which was heated to different temperatures, and examined from time to time, old papules having been previously marked. The patients were clothed, but kept at rest during the experiment. They were tested as soon as possible after arrival at hospital, for it was considered that, once having left their homes, they had almost certainly left behind them the real cause of the disease, whether this were food or not; and delay might therefore vitiate the experiment. Accordingly each patient could serve for one experiment only. In some ways it would be preferable to test each patient to a series of different temperatures for it is possible that those who did not react at the lower temperatures would not have done so at the higher. 
Eight observations were made, the results of which are shown in the following table :-

TABLE 5.

\begin{tabular}{|c|c|c|c|}
\hline CASE & $\begin{array}{c}\text { Room } \\
\text { TEMPERATURE. }\end{array}$ & $\begin{array}{c}\text { Duration of } \\
\text { Exposure. }\end{array}$ & Result. \\
\hline I.c. & $\begin{array}{l}\text { GREES } \\
\text { 64. }\end{array}$ & 1 hour & No fresh lesions. \\
\hline D.R. & 65 & , & No fresh lesions. \\
\hline B.H. & 67 & ," & No fresh lesions. \\
\hline R.M. & 68 & ," & One fresh wheal. \\
\hline R.A. & 68 & , & Three fresh wheals. \\
\hline $\begin{array}{l}\text { W.W. } \\
\text { G.B. }\end{array}$ & 70 & $"$ & $\begin{array}{l}\text { Many fresh wheals. } \\
\text { Few fresh wheals. }\end{array}$ \\
\hline I.A. & 70 & 15 minutes & Many fresh wheals \\
\hline
\end{tabular}


carbohydrate content of the diet. The patient with diarrhoea, and the two with constipation were specially chosen on account of these symptoms. These digestive disorders did not show the same dramatic improvement as the rash and therefore cannot be regarded as the exciting causes. The patient with diarrhoea was specially interesting. She was in hospital for seven weeks, during which time no fresh lesions occurred. Yet, although the diarrhoea had ceased, she developed a fresh crop of papules the day after her discharge. Allergy to pork fat seems to be out of the question, since thirteen of the patients were given bacon, while another patient had never received any pork in her life.

It is admittedly difficult to be absolutely certain that the home diet is reproduced with perfect accuracy. These experiments show, however. that the number of foods which could be responsible for the symptoms in any one case must be strictly limited. Yet, that being so, why is it so very difficult to detect the offenders by careful history taking? Further, it must be emphasized that papular urticaria is of so frequent occurrence that the foods responsible, if food allergy were indeed the cause, must be common articles of diet and it is almost inconceivable that the particular food should have been overlooked in every one of these experiments. There seems, indeed, hardly room for doubt that papular urticaria is not a manifestation of food allergy; the cause must be sought in the child's environment.

3. Environmental influences.-In the following experiments, the same precautions as before were observed with regard to ward temperature, and the carbohydrate content of the diet.

Bedding.- In two cases bedding from the patients' homes was substituted for the usual hospital bedding. In one case the test was completely negative, and it is therefore unlikely that the bedding was the cause of the symptoms when the child was at home. In the second case a positive result was obtained :-

B.G., a male, aged seven years, had been subject to papular urticaria for five years. The rash was profuse, especially on the limbs and back, and a few lesions were present on the face. He was admitted to hospital on June 26, 1933, and in addition to the ordinary hospital diet, he was given bacon, chocolate, bananas and porridge. There was an immediate improvement, no fresh wheals appearing. On July 5 bacon was discontinued. On July 7 bedding from home was substituted for the hospital bedding. On the following day well-marked fresh lesions of papular urticaria were present. He continued to sleep on this bedding for a further ten days, but although the ward temperature was kept high, reaching $75^{\circ} \mathrm{F}$. on occasions, no further outbreak occurred. On the second day after his return home, however, fresh wheals were observed.

Here, one crop of fresh papules appeared. It is tempting to incriminate the bedding, but if that were responsible, it seems strange that only one attack occurred during the boy's stay in hospital, whereas fresh 
wheals were appearing almost daily when he was at home. It seems much more likely that the boy was sensitive, not to the actual bedding, but to something which was carried into hospital with it; and this agent was removed by the making of the bed and cleaning of the ward.

In one other instance I have witnessed an outbreak of papular urticaria during a patient's stay in hospital. This I saw by the courtesy of Prof. L. G. Parsons.

N.J., a male, aged four years, suffering from osteogenesis imperfecta, was admitted to the General Hospital, Birmingham, on September 3, 1933. On the morning of October 4 the cutaneous eruption was observed. The lesions were scattered over the forearms, legs, and back, and appeared in every way typical of papular urticaria. A careful inquiry showed that there had been no change from the ordinary hospital diet and the administration of the same food on subsequent days was without any untoward effect. It was discovered, however, that on the day preceding the outbreak of the rash, a woollen vest, pyjamas and dressing jacket had been brought from home, and these the boy had worn during the rest of that day. He continued to wear them for several more days, but no further lesions appeared.

In this case, the outbreak of the rash seemed to be definitely related to the wearing of clothes brought from home, and, in view of the other experiences, this association of events cannot be dismissed as pure coincidence. Yet here again, it seems unlikely that the clothes themselves were responsible, because, although the patient wore them for several days, there was only one crop of papules. Hallam made similar tests with bedding in four cases, with a positive result in one. Here a repetition of the test was negative.

In each of three patients, one of Hallam's and the two just described, fresh lesions of papular urticaria have appeared while the patient has been in hospital. In each instance the outbreak occurred only after the patient had slept on bedding, or in clothes, brought from home. Moreover, these are the only cases in which I have known the rash to appear during a patient's stay in hospital, although many other efforts have been made to provoke it. Accordingly there can be little doubt that the attacks were in some way connected with the bedding and clothes. It is unlikely that these articles were themselves responsible for the symptoms, because in each of my two cases there was only one fresh crop of papules, and in Hallam's case, although fresh lesions appeared on several days, a repetition of the experiment gave a negative result. Further, the introduction of home bedding into hospital did not provoke the rash in other cases. The most reasonable conclusion seems to be that the eruption was due to something carried on the bedding and clothes respectively.

The precise nature of this agent remains obscure. The following substances were tested, but with negative results in each case :-

House DUST.-Sweepings from a patient's bedroom were scattered into the air of the ward, and on to the bed. The experiment was performed once only, and although the ward temperature reached 
$69^{\circ}$ F., it was not maintained at this level. The test will be repeated when a suitable opportunity occurs.

Moulds.-In three cases, spores of moulds cultured from the air of the bedrooms were scattered above the patients' beds. It cannot be assumed that the growths obtained accounted for the whole mould flora of the bedrooms : while it is evident that the children were not sensitive to moulds in general, sensitivity to a particular mould is not definitely excluded.

SCRAPINGs From walls and ceilings.-Similar tests were performed with the fine dust obtained by scraping the walls and ceilings of the bedrooms.

Animal size.-This substance was tested because it is present on the walls or ceilings of most houses, and animal emanations are supposed to be among the commoner causes of allergy. Large sheets of paper coated with size were hung round the bars of a cot for several days, and very finely-ground size was scattered into the air of the ward.

Hutchinson and Burnet regarded flea bites as the commonest causes of the disease, and the possibility of insect bites has also been mentioned by Crocker, Barber, Weigart and Boutelier. It is obvious that each individual wheal does not represent a separate bite, because neither flea bites nor bug bites produce the typical papules. Further, it has been shown that, with out-patients, fresh lesions may be evoked simply by raising the atmospheric temperature; it is inconceivable that these children harbour an insect which bites only on the application of warmth. Insect bites could, of course, act indirectly, by introducing some toxin into the blood stream, but the very frequent occurrence of the disease in all grades of society seems to negative such a possibility.

Hallam's discovery that admission of patients to hospital for nights only, relieves the symptoms, excludes sensitization to antigens derived from human beings or domestic animals. The children would be in much closer contact with domestic animals during the day than during the night. With regard to the possibility of antigens derived from human beings, it may be added that several of the present series of patients, when sleeping at home, occupied not only separate beds but also separate bedrooms.

To sum up, all the evidence points to the following conclusions. Some external influence is necessary to provoke the rash. This agent is not a food, but is something in the environment. It is not bedding or clothes, but it can be carried on those articles. It is not vermin, nor an antigen derived from human beings or domestic animals. The evidence relating to house dust, and to moulds or bacteria which it may contain, is inconclusive.

Quite apart from any experiments, it is indeed remarkable that the occurrence of papular urticaria among ordinary patients in children's wards is an event of the greatest rarity. Yet these children are being treated for a great diversity of digestive disorders and febrile illnesses, as well as for rickets and other complaints, and they receive a variety 
of diets. Surely this in itself points to some environmental factor as the exciting cause of the disease. It is noteworthy that change of residence, other than admission to hospital, may influence the complaint, as pointed out by Hardy and Kinnear. Nearly all the patients of the present series were living in the houses in which they were born, but in eight cases, change of residence seemed to have a striking effect.

There can be no doubt that sufferers from papular urticaria possess a special sensitivity to the exciting agent; everyone must be familiar with instances where, of two children living under the same conditions and sleeping in the same bed, one develops the eruption and the other remains unaffected. It seems quite justifiable, therefore, to speak of the complaint as an allergic disease, even though the allergen remains undiscovered.

As in other allergic diseases, the sensitivity seems to vary, and in practically all cases it disappears in late childhood.

Papular urticaria shows a further similarity to other allergic diseases in that patients exhibit an increased cutaneous sensitivity to foreign proteins.

In some cases, too, changes in the blood may be observed, which, though not very convincing, are perhaps suggestive of an allergic reaction. These and other blood changes will be briefly discussed in the following paragraphs.

\section{Blood examination.}

Haematology. - A leucocyte count was made in ten cases. Fresh wheals were present in all the patients, but the skin lesions can only be regarded as a rough guide to the stage of the reaction (table 6).

TABLE 6

Leucocyte Count in Papular Urticaria.

\begin{tabular}{|c|c|c|c|c|c|c|}
\hline \multirow[b]{2}{*}{ CaSe } & \multirow[b]{2}{*}{$\begin{array}{l}\text { TOTAL LEUCO- } \\
\text { CYTE COUNT. } \\
\text { PER C.MM. }\end{array}$} & \multicolumn{3}{|c|}{ DifferentT } & \multirow{2}{*}{$\begin{array}{l}\text { CENT. OF } \\
\text { EOSINO- } \\
\text { PHILS. }\end{array}$} & \multirow{2}{*}{$\begin{array}{c}\text { White } \\
\text { Baso- } \\
\text { PHILS. }\end{array}$} \\
\hline & & $\begin{array}{c}\text { PoLY- } \\
\text { MORPHS. }\end{array}$ & $\begin{array}{l}\text { LYMPHO- } \\
\text { CYTES. }\end{array}$ & $\begin{array}{l}\text { MONO- } \\
\text { CYTES. }\end{array}$ & & \\
\hline E.S. & 8,900 & 44 & 44 & 10 & 2 & - \\
\hline B.G. & $\begin{array}{r}\mathbf{0}, 100 \\
\mathbf{1 3}, 100\end{array}$ & 45.5 & 36 & 4.5 & 13.5 & 0.5 \\
\hline J.Th. & 6,550 & 45.5 & 40.5 & 8.0 & 6.0 & - \\
\hline J.T. & 10,050 & - & - & - & 3 & - \\
\hline & 11,750 & 58 & 27 & 13 & 2 & - \\
\hline & 10,100 & 37.5 & 59.5 & 2 & 1 & - \\
\hline & $\begin{array}{r}10,100 \\
7,900\end{array}$ & 29 & 62.5 & 5.5 & 2 & 1 \\
\hline & 14,500 & 14 & 77.5 & 8 & 1. & \\
\hline B.A. & 14,200 & 64 & 30.5 & 3.5 & & - \\
\hline T.A. & 8,100 & 49.5 & 43 & 4.0 & 3.5 & - \\
\hline
\end{tabular}

There was no constant finding; three cases showed a definite lymphocytosis, and two a well-marked eosinophilia. One patient, B.G., who had a high degree of eosinophilia, was admitted to hospital, when two further counts were made, and neither of these revealed any abnormality. It is probable, therefore, that the blood change in this case was directly connected with the presence of the rash, a further point in support of the allergic basis of the disease. 
Hallam observed a leucopenia and eosinophilia in four out of five cases; Corson found eosinophilia in seven out of twenty-five cases.

Blood chemistry. Amino-Acids and Chlorides.-It was thought possible that at the height of an attack the blood might show changes similar to those found by Barber and Oriel in other allergic conditions, viz., an increase in the amino-acid value and a reduction of chlorides. Estimations were carried out in thirteen cases, but the results were inconsistent and mainly negative, and the investigation was therefore abandoned. There were a few findings which may be of some significance. As controls, three patients were admitted to hospital and the estimations repeated when the rash had disappeared. Examinations were made also in three cases of mild impetigo. The results are given in table 7.

TABLE 7.

OUT-PATIENTS : FRESH IN-PATIENTS : NO WHEALS WHEALS PRESENT. PRESENT.

$\begin{array}{cccc}\text { Amino- } & \text { Chlorides } & \text { AMINo- } & \text { Chlorides } \\ \text { ACID-N. } & \text { MGM. } & \text { ACID-N. } & \text { MGM. } \\ \text { MGM. } & \text { PER CENT. } & \text { MGM. } & \text { PER CENT. } \\ \text { PER CaNt. } & & \text { PER CENT. } & \end{array}$

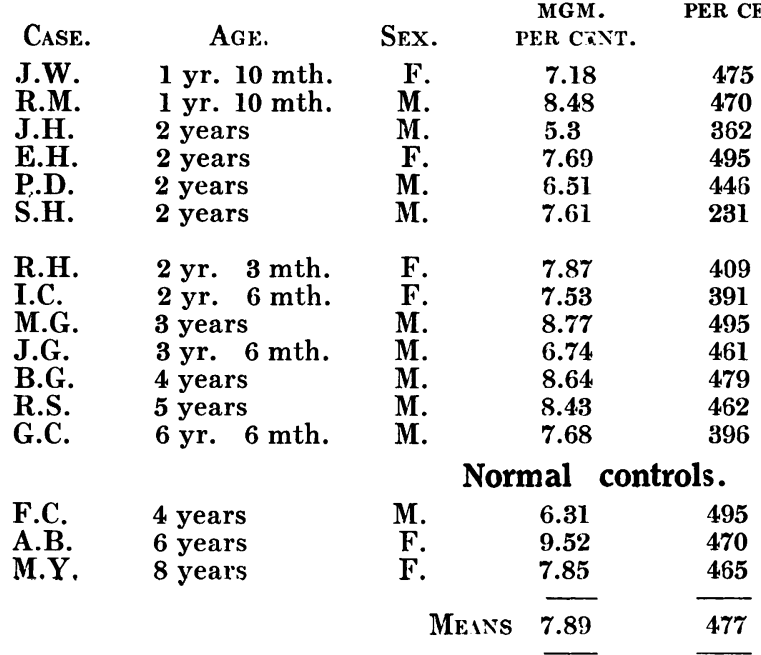

The commonly accepted figure for the normal value of the blood chlorides (whole blood) is $\mathbf{4 5 0 - 4 9 5} \mathrm{mgm}$. per cent. According to Edgar, the figures obtained for the amino-acid nitrogen when estimated by Folin's method-the method adopted here-show variations depending on the strength of the sodium carbonate solution employed. The values obtained in the present series are higher than those of most observers, but are commensurate with those obtained by Edgar. It will be observed that in no case was the presence of wheals associated with any increase of the amino-acid nitrogen, but in five cases there was a definite reduction in the chlorides. Since the variations of the amino-acids and chlorides which occur in allergic reactions are transitory, no conclusions can be drawn from the negative results of single estimations. The lowering of the chlorides, however, may be of some significance and this seems the more probable because in two cases where it was observed, the figures 
returned to normal when the rash had subsided. Corson found a slight reduction of the chlorides in twelve out of sixteen cases.

Alkali Reserve.-It has been suggested that the administration of alkalies has a beneficial effect in some cases of papular urticaria. The $\mathrm{pH}$ of the blood and the alkali reserve were therefore estimated in three cases. The $\mathrm{pH}$ was determined electrically, the hydroquinone electrode being employed, and the $\mathrm{CO}_{2}$ was estimated by van Slyke's method.

In one case two estimations were carried out, one on the morning following the child's admission to hospital, the second on the day of discharge. In the other two cases a single estimation was made when the child had been in hospital a week. In each instance the blood was collected after a twelve hours' fast. The results are summarized in table 8 .

TABLE 8.

\begin{tabular}{|c|c|c|c|c|c|c|}
\hline CASE. & 4 years & $\begin{array}{l}\text { ALKaLI } \\
\text { SEX. }\end{array}$ & $\begin{array}{l}\text { RESERVE IN } \\
\text { pH. } \\
\text { (i) } 7.53\end{array}$ & $\begin{array}{c}\text { Papular URT } \\
\mathrm{CO}_{2} \\
22 \text { millimols }\end{array}$ & RIA. & $\begin{array}{l}\text { REMARKS. } \\
\text { wheals two }\end{array}$ \\
\hline D.R. & 4 years & M. & $\begin{array}{l}\text { (i) } 7.53 \\
\text { (ii) } 7.56\end{array}$ & $\begin{array}{l}22 \text { millimols } \\
25.6\end{array}$ & $\begin{array}{l}\text { Fresh } \\
\text { after }\end{array}$ & $\begin{array}{l}\text { wheals two } \\
\text { discharge. }\end{array}$ \\
\hline B.G. & 7 years & M. & (i) 7.53 & $22.5 "$, & $\begin{array}{c}\text { Fresh } \\
\text { disch }\end{array}$ & $\begin{array}{l}\text { wheals day } \\
\text { arge. }\end{array}$ \\
\hline .B. & 9 years & M. & 7.41 & 27 & $\begin{array}{l}\text { Fresh } \\
\text { after }\end{array}$ & $\begin{array}{l}\text { wheals two } \\
\text { discharge. }\end{array}$ \\
\hline
\end{tabular}

Normal values were obtained in each case, yet each relapsed almost immediately after his discharge from hospital. It is obvious, therefore, that a lowered alkali reserve is in no wise an essential condition for the development of papular urticaria and a normal alkali reserve seems to afford no protection.

\section{Treatment.}

Many children suffer from transient attacks of papular urticaria, and recover without treatment, an important fact which must always be borne in mind in any attempt to estimate the value of a particular remedy. Treatment is tested by the chronic cases, and, only too frequently, it proves far from satisfactory.

Since heat has such a profound influence on the symptoms, much can often be accomplished by attention to clothing and to ventilation of the patients' bedrooms. Most authors advocate dietetic treatment, but many are extremely vague in their instructions, while some give advice diametrically opposed to that of others. I am convinced that in many cases restriction of the carbohydrate content of the diet has a very beneficial effect.

It is customary to prescibe medicine, if only for the peace of mind of the parents. In this country, soda and rhubarb seems to be the traditional remedy. Thus, Lancashire writes, 'If I had the choice of one drug only it would be rhubarb and soda.' I have prescribed such a mixture in the majority of my cases, and its administration has frequently been followed by improvement. In some cases, at any rate, the benefit was probably due to the medicine, since the substitution of other drugs was followed by relapse, improvement occurring again on the re-administra- 
tion of soda and rhubarb. Paterson advises large doses of sodium bicarbonate. Bray gives hydrochloric acid and pepsin, although, if, as he states, the disease were a manifestation of fat allergy, the rationale of this mixture is somewhat obscure. The observations which I have recorded on the alkali reserve, while in no way conclusive, are perhaps a little suggestive that neither alkaline nor acid therapy is likely to be of much value.

Calcium is not infrequently given, although blood analysis shows a normal serum calcium in most cases. Cornbleet advises injections of parathyroid extract combined with the oral administration of calcium lactate in large amounts. Such treatment would increase the serum calcium even if the calcium lactate were omitted. Another method which would tend to increase the serum calcium is the production of an acidosis. I gave calcium chloride, 10 grains three times a day, to two patients (aged three years and three years nine months respectively) but the parents of both stated that the symptoms were aggravated by the treatment. I have never seen benefit accrue from the administration of other calcium compounds in ordinary doses. Darier and van Vonno prescribe atophan, but it is a drug not free from danger and its use in a relatively harmless disease does not seem justifiable. Desensitization with peptone has been attempted, and Urbach claims a high degree of success for his propeptan method. Good results have been recorded also by Pasteur Vallery-Radot and Blamoutier, from the oral administration of less specific peptones, and by Mathieu, Levy and Lautman from the intradermic injection of Witte's peptone.

Admission of patients to hospital always brings relief, and in my cases, although relapse occurred when they returned home, the symptoms were much less severe than before. This seems to be by far the most valuable therapeutic measure in all those severe and persistent cases where the general health suffers from the continual irritation and loss of sleep.

\section{Conclusions.}

1. Papular urticaria is a definite and distinct syndrome, separable from urticaria and from Hebra's prurigo.

2. It is a manifestation of allergy.

3. It is essentially a disorder of the first four years of life.

4. It is aggravated by heat, and by a diet containing too much carbohydrate.

5. Digestive disorders, teething and mild febrile disturbances probably predispose to papular urticaria, but such conditions are of very minor importance in its aetiology. Rickets plays no part.

6. There is no satisfactory evidence of any underlying diathesis.

7. The exciting agent is not a food.

8. The exciting agent is something connected with the patients' home environment, but its precise nature remains obscure. It is not bedding or clothes, but it can be carried on these articles. It is not 
vermin, animal-size, nor an antigen derived from human beings or domestic animals. Sensitivity to house-dust has not been definitely excluded.

I am greatly indebted to Miss Hickmans, Ph.D., Biochemist to the Children's Hospital, for the biochemical estimations, and to Dr. J. C. Hawksley, late Research Scholar at the Hospital, for the blood counts. My thanks are also due to the nursing and administrative Staffs for their helpful co-operation in the experimental investigations.

\section{REFERENCES}

Adamson, H. G., Diseases of Children, Garrod et alii, Lond., Second edition, 1929, 1042.

Balyeat, R. M., Am. J. Med. Sci., Philad., 1928,, CLXXVI, 332.

Barber, H. W. \& Oriel, G. H., Lancet, Lond., 1928, ii, 1009, 1064.

Bateman, T., Practical Synopsis of Cutaneous Diseases, Lond., 1813.

Boutelier, A., Quelques Dermatoses Communes de l'Enfance, Paris, 1930.

Bray, G. W., Brit. J. Child Dis., Lond., 1933, XXX, 180; Brit. Med. J., Lond., 1930, i, 384.

Burgess, N., Brit. Med. J., Lond., 1928, ii, 1010.

Burnet, J., Internat. Clin., Philad., 1923, III, 198.

Chisholm, C., Brit. J. Child Dis., Lond., 1933, XXX, 83.

Civatte, A., Ann. de dermat. et syph., 1926, VII, 142.

Comby, J., Traite des Maladies de l'Enfance, Paris, Seventh edition, 1928.

Cooke, R. A., \& Vander Veer, A., J. Immunol, Baltimore, 1916, I, 201.

Cornbleet, T., Arch. Dermat. \& Syph., Chicago, 1929, XIX, 289.

Corson, E. F., et al., Arch. Pediat., New York, 1931, XLVIII, 349.

Crocker, H. Radcliffe, Dis. of the Skin., Lond., Third edition, 1903, 120, 132.

Czerny, A. D., Jahrb. f. Kinderh., Berlin, 1905, XI, 199.

Duhring, L. A., Dis. of the Skin, Philad., Third edition, 1889, 160.

Edgar, S. H., Biochem. J., Lond., 1928, XXII, 163.

Fox, Tilbury, Skin Diseases, Lond., Third edition, 1873, 124.

Funk \& Grunzach, Monatsch. f. prakt. Dermat., 1894, XVIII, 109.

Gebert, E., Arch. f. Kinderh., Berlin, 1891, XIII, 185.

Gray, A. M. H., Practitioner, Lond., 1922, CIX, 72.

Hallam, R., Brit. J. Dermat., Lond., 1927, XXXIX, 95; 1932, XLIV, 117.

Hardy, A., Traite des Maladies de la Peau, Paris, 1886, 297.

Haxthausen, H., Zentralbl. f. Haut u. Geschlechtskr.. Berlin, 1924-25, XV, 332.

Heath, A. D., Proc. Roy. Soc. Med., Lond., 1911-12, V, pt. 1, 194.

Hellsten, H., Brit. Med. J., 1934, i, Epit., p. 33.

Hutchinson, J., Lectures on Clinical Surgery, I, pt. I, Lond., 1878.

Karplus, D., Monatschr. f. Kinderh., Berlin, 1928, XXXVIII, 234.

Kinnear, J., Brit. J. Dermat., Lond., 1933, XLV, 65.

Lancashire, G. H., Brit. Med. J.. Lond.. 1928, ii, 1196.

Lewis, T., Blood Vessels of the Human Skin, Lond., 1927.

Leroy, E., \& Mathieu, R.. J. de med. et chir. prat., Paris, 1930, CI, 661.

Lortat-Jacob, L., La Médicine, Paris, 1929, X, 862.

Mathieu, R., \& Vasseur, N., Arch. d. mal. de l'app. digestif, Paris, 1930, XX, 332.

Mathieu, R., Levy, G., et Lautman, N., Bull. Soc. de pédiat. de Paris, Paris, 1932, XXX, 251.

Montgomery, D. W., Arch. Pediat. New York. 1917, XXXIV, 910.

O'Keefe, E. S., \& Rackemann, F. M., J. Am. Med. A s.3.. Chicago, 1929, XCII, 883.

Park, E. A., \& Eliot, M. M., Dis. of Infancy and Childhood, Edited, Parsons, L. G., and Barling, S., Lond., 1933, 227.

Paterson, D., Sick Children, Lond.. 1930.

Shannon, W. R., Am. J. Dis. Child., Chicago, 1921. XXII, 223.

Sidlick, D. M., \& Knowles, F. C.. Ibid., 1922, XXIII, 316.

Spain, W. C., \& Cooke, R. A., J. Immunol., Baltimore, 1924, IX, 521.

Stuart, H. C.. Am. J. Dis. Child., Chicago. 1923. XXV, 135.

Urbach, E.. Skin Disease, and Nutrition, (Eng. Trans.), Vienna, 1932, 169.

Vallery-Radot, Pasteur \& Blamoutier, P., Paris méd., Paris, 1926, I. 398.

Van Vonno, N. C.. Nederl. tiidschr. v. geneesk.. Amsterdam, 1930, II, 5699.

Walker,.. N., Introduction to Dermatology. Edinburgh. Ninth edition, 1932.

Weigart. R., Monatschr. f. Kinderh.. Berlin. 1923. XXV, 669.

Whitfield, A., Proc. Roy. Soc. Med., Lond., 1911-12, V., pt. I, 188, 